\title{
Elite Studies: For a NeW Approach
}

\author{
Erzsébet Bukodi* \\ Department of Social Policy and Intervention, \\ Nuffield College \\ University of Oxford \\ Erzsebet.bukodi@nuffield.ox.ac.uk
}

John H. Goldthorpe

Nuffield College

University of Oxford

John.goldthorpe@nuffield.ox.ac.uk

Forthcoming in Political Quarterly

* Nuffield College, New Road, Oxford, OX1 1NF, UK 


\section{ABSTRACT}

After a period in which interest in elites among social scientists went into decline, elite studies are now reviving. But it is important to understand why the decline occurred. We critically examine the largely contradictory explanations put forward by Scott and Savage and their related proposals for new research. We suggest an alternative approach that, we believe, would prove more rewarding. This entails treating elites quite extensively, but understood as small-N entities, clearly distinct from social classes. On this basis, elites can be characterised through prosopographical methods - the construction of collective biographies of their members. More reliable accounts can thus be produced of the social composition of different elites and in turn questions addressed of how far skewness in their recruitment results from the processes through which they are formally constituted and how far from the composition of the 'pools' from which their recruitment primarily occurs. Further questions follow of the implications not only for equality of opportunity but also for the wastage of talent and loss of diversity in elite memberships and for the so far neglected issue of the quality and the effectiveness of elites in whatever field they exist.

KEYWORDS: elites; social origins; equality of opportunity; prosopography 
INTRODUCTION

In the closing decades of the last century interest in elites among social scientists tended to wane. In Britain, the collection of papers edited by Stanworth and Giddens ${ }^{1}$ can be seen as something of a watershed. Research of the kind represented in this volume, which had previously flourished, showed no strong continuation in the years that followed. However, of late, elites would again appear to be attracting attention, and in a political as well as in a purely social scientific context. The Social Mobility Commission (SMC) has published two reports on elites in Britain, focusing on social inequalities in access to elite positions and the resulting lack of diversity in elite composition. ${ }^{2}$ And the work of Piketty ${ }^{3}$ has led to wide-ranging discussion of the emergence, and of the economic and political significance, of new 'wealth elites'. Under these, and various other, influences, research on elites is now reviving in Britain and elsewhere.

The question does nonetheless remain important of why it was that elite studies went into a period of eclipse. If the reasons for this are not appreciated, the clear danger exists that mistakes of the past will be repeated. In this paper, we have then two aims. The first is to provide a critique of two kinds of explanation that have been offered for what was in effect the previous failure of elite studies. The second is to outline a new approach that, we believe, would avoid the serious problems encountered in the past and lead to more productive and progressive research.

\footnotetext{
${ }^{1}$ P. Stanworth and A. Giddens (eds.), Elites and Power in British Society, Cambridge, Cambridge University Press, 1974.

2 Social Mobility Commission, Elitist Britain?, London, Social Mobility Commission, 2014; Elitist Britain 2019, London, Social Mobility Commission, 2019.

${ }^{3}$ T. Piketty, Capital in the $21^{\text {st }}$ Century, Cambridge, Mass., Harvard University Press, 2014.
} 


\section{CRITIQUE}

We focus on the two different, and in important respects conflicting, explanations for the decline in elite studies as these have been most fully advanced by John Scott and Mike Savage.

Scott's explanation of why research into elites 'faltered' is an internalist one, focusing on difficulties that arose within this field of study. ${ }^{4}$ At the root of these difficulties, Scott argues, was a tendency for the term 'elite' to be used in a too undiscriminating way: that is, to apply not only to groups holding power in society but further to any group or category that was in some sense advantaged, qualified, privileged or superior. As a result, the concept of an elite became increasingly devoid of distinctive reference. In particular, Scott is critical of the confusion that was created between the concepts of elites and classes. Elites, he maintains, have to be treated as analytically distinguishable from social classes 'no matter how entwined they may be in real situations' - as, for example, through processes of recruitment.

If therefore elite studies are to be successfully revived, it is essential, in Scott's view, that the conceptual linkage between elites and power should be restored. Only those groups should be regarded as elites that 'hold or exercise domination within a society or within a particular area of social life'. If, for example, an economic elite is to be identified, what is important is not whether its members are wealthy capitalists or highly paid managerial employees but whether they form 'an inter-organizational group of people' who can actually be shown to dominate within the corporate world.

\footnotetext{
${ }^{4}$ J. Scott, 'Modes of Power and the Re-Conceptualisation of Elites', Sociological Review, vol. 56, 2008, pp. 25-43.
} 
In contrast, the explanation put forward by Savage for the decline of elite studies is an externalist one..$^{5}$ Elite studies, usually based on documentary or ethnographic research, became marginalised, Savage claims, as a result of the growing predominance in the study of social stratification of large-scale survey research. Pluralism in methodology was dispelled. And at the same time elite studies were neglected because of the difficulty that sociologists found in moving away from the 'problematic of the proletariat' - from questions of the composition, boundaries and solidarity of the working class and of their political implications.

In Savage's view - and again in direct contrast to Scott's - what is then important for the future of elite studies is that the divergence in research on elites and on social class should be overcome. The two fields of enquiry have to be re-integrated by 'theorising' elites within class analysis, and with particular reference to the wealth elites identified by Piketty.

We would agree with Scott that elite studies faltered primarily because of problems encountered within the field. Savage's externalist account lacks any serious documentation. However, we would not follow Scott in the claim that these problems came about from the concept of elites being too indiscriminately applied. To the contrary, they resulted from the very focus of elite studies that Scott believes should be re-established: that is, on the relation between elites and power. Wright Mills' study of the US 'power elite' and the critical responses to it from the 'pluralist' positions of Dahl, Polsby and others triggered a long and often ideologically charged debate but one which led to very little substantive progress. ${ }^{6}$ And what

\footnotetext{
${ }^{5}$ M. Savage and K. Williams, 'Elites: Remembered in Capitalism and Forgotten by Social Sciences', Sociological Review, vol. 56, 2008, pp. 1-24; M. Savage, 'Introduction to Elites: From the "Problematic of the Proletariat" to a Class Analysis of "Wealth Elites", Sociological Review, vol. 63, pp. 223-39.

${ }^{6}$ C. W. Mills, The Power Elite, New York, Oxford University Press, 1959; R. A. Dahl, Who Governs? Democracy and Power in an American City, New Haven, Yale University Press, 1961; N. Polsby, Community Power and Political Theory, New Haven, Yale University Press, 1963.
} 
was then, and still remains, the crucial but unanswered question is the following. Is it possible - and, if so, how - to move on from analyses of the recruitment of elites and of commonalities and interrelations existing within and among elites to show that such analyses are informative as to the ways in which, and ends towards which, elites actually exercise power?

Already in the Stanworth-Giddens collection challenging 'so what' issues were raised. Hewitt pointedly asked, à propos the work of Domhoff on the supposed American power elite, if it remains unclear how, and how far, the social background of decision-makers affects their decisions, 'then why study it - apart from the intrinsic interest of studying mobility in any area'. And Kelsall suggested that 'the honest answer' to the question of what effect the social origins of elite members has on their attitudes and behaviour has to be that they 'would not necessarily be altered in any predictable direction' if their backgrounds were different. ${ }^{7}$

Just the same issues do then arise in the case of recent research which falls in line with Scott's programme. For example, Larsen and Ellersgaard, claiming a Danish power elite, and Hjellbrekke et al., claiming a plurality of elites within a 'field of power' in Norway, present detailed analyses of the social composition and networks of elites. But in neither study is any attempt made - as, say, through particular case studies - to show how these analyses relate to, and illuminate, the ways in which elites actually use their power, in concert or in conflict and whether directed towards common or divergent ends. ${ }^{8}$

\footnotetext{
7 C. J. Hewitt, 'Elites and the Distribution of Power in British Society' in Stanworth and Giddens, eds.; W. G. Domhoff, Who Rules America? Englewood Cliffs, Prentice-Hall, 1970; R. K. Kelsall, 'Recruitment to the Higher Civil Service: How has the Pattern Changed? in Stanworth and Giddens, eds. Underlying these sceptical positions, one may suggest, was the study, at the time influential, though now largely forgotten, of T. Lupton and C. S. Wilson, 'The Social Background and Connections of "Top Decision Makers"', The Manchester School of Economic and Social Studies, vol. 27, 1959, pp. 30-51.
}

${ }^{8}$ A. G.Larsen and C. H. Ellesgaard, 'A Scandinavian Variety of Power Elite? Key Institutional Orders in Danish Elite Networks' in O. Korsnes, J. Heilbron, J. Hjellebrekke, J. Bühlmann and M. Savage eds., New Directions in Elite 
In short, to wish to treat studies of the formation of elites primarily as a means of understanding the nature and objectives of 'domination' would seem, perversely, to restrict the field to an area in which little has been achieved in the past and in which there are still few signs of long-standing problems being overcome. ${ }^{9}$

Turning to Savage's proposal for the re-integration of elite studies with class analysis and with a focus on newly emergent wealth elites, what we find disturbing in the research programme that has been followed is the constant shifting of ground in the way in which a wealth elite is defined and related to a class. Integration is less evident than confusion.

Problems initially derive from the use made of the Great British Class Survey (GBCS) of 2011. ${ }^{10}$ The heavy bias among the GBCS self-selected respondents towards those in more socially advantaged positions gives sufficient numbers, Savage maintains, to allow 'granular' analyses to be made at the higher levels of the class structure. Elite formation can thus be studied in a way not possible with research drawing on nationally representative samples and using the National Statistics Socioeconomic Classification (NS-SEC).

On the basis of the GBCS, Savage and his associates claim to identify an elite which comprises 6 per cent of the adult British population. This is a surprisingly large proportion for an elite, being not that much smaller than NS-SEC Class 1 and in fact larger than NS-SEC subdivision,

Studies, London, Routledge, 2018; J. Hjellbrekke et al., 'The Norwegian Field of Power: Anno 2000', European Societies, vol. 9, 2007, pp.245-73.

${ }^{9}$ For example, B. Cousin, S. Khan and A. Mears, 'Theoretical and Methodological Pathways for Research on Elites', Socio-economic Review, vol. 16, 2018, pp. 5-49 attempt to address 'some of the major challenges to research' in elite studies and recommend a 'greater attentiveness to and specificity about the relationship between elites and power'. But it is notable they give no clear indication of how they believe that any advance in this regard might be made.

${ }^{10}$ M. Savage et al., 'A New Model of Social Class? Findings from the BBC's Great British Class Survey Experiment', Sociology, vol. 47; 2013, pp. 219-50; M. Savage et al., 'On Social Class, Anno 2014', Sociology, vol. 49, 2015, pp. 1011-30. 
1.1, that of higher managers and administrators. Indeed, Savage et al. do subsequently describe their elite as 'fundamentally a senior corporate managerial group'. ${ }^{11}$ But what is then all too evident is that the GBCS elite is far too large and not nearly wealthy enough to be seen as a wealth elite in the sense of Piketty: that is, one made up of capitalist rentiers and 'supermanagers'. The household incomes of the GBCS elite averaging less that $£ 90,000$ p.a. and their savings averaging under $£ 150,000$ are small potatoes as compared with those of members of the elite that Piketty equates with the top $1 \%$ in the total income (i.e. capital plus labour income) distribution. ${ }^{12}$

This discrepancy is then more or less openly recognised by Cunningham, who claims that he and Savage have shown that the GBCS elite 'closely resembles established and validated notions of a social elite' in the form of NS-SEC Class 1. He has therefore necessarily to concede that this elite cannot be equated with a wealth elite. It has rather to be understood as a new 'ordinary' elite - a rather odd and not obviously helpful notion. ${ }^{13}$

Presumably in response to these difficulties, Savage and Nichols move on to consider a subgroup within the GBCS elite - that of the 'super-rich' -- made up of individuals aged over 22 and living in households with net incomes of $£ 200,000$ a year or more. ${ }^{14}$ In this way, a closer approximation to a wealth elite is achieved. But what then transpires is that the interest in such

\footnotetext{
11 Savage et al., 'A New Model of Social Class', Table 5; 'On Social Class, Anno 2014'.

12 Savage et al., 'A New Model of Social Class', Table 6; Piketty, Capital in the $21^{\text {st }}$ Century, ch. 7 and Table 7.3.

13 N. Cunningham, 'Making and Mapping Britain's “New Ordinary Elite”, Urban Geography, vol. 40, 2019, pp. 60426; N. Cunningham and M. Savage, 'The Secret Garden? Elite Metropolitan Geographies in the Contemporary UK', Sociological Review, vol. 63, 2015, pp. 321-48.

${ }^{14}$ M. Savage and G. Nichols, 'Theorizing Elites in Unequal Times: Class, Constellation and Accumulation' in Korsnes et al., New Directions in Elite Studies.
} 
an elite is not, as with Piketty, in its economic and potential political importance. The questions that are now taken up are the quite different ones of how far the super-rich 'have distinctive cultural and social attributes' and how far in these respects 'they might deviate from the traditional and "highbrow" forms' that were characteristic of an earlier 'upper class'.

Finally, though, in seeking to pursue these questions, Savage and associates revert, more or less indifferently, to data relating to the GBCS elite and to NS-SEC Class 1 as well as to the super-rich. ${ }^{15}$ They make analyses of social and geographical mobility into what are generically described as 'elite positions' and of the lifestyles and outlook of those holding such positions. On this basis, their main conclusion is that insofar as a new elite is emerging in Britain, it is not especially marked out by its modes of recruitment or by its subculture. And they therefore maintain that their findings call into question Piketty's argument of there being a 'return to the inherited elite class of the belle epoch'. It has, however, again to be said that results based either on the GBCS elite or on NS-SEC Class 1 can have little bearing on the validity of Piketty's claim since collectivities of quite differing magnitudes are involved. ${ }^{16}$

In sum, the research in question is characterised by a persisting equivocation over how a wealth elite is to be conceptualised and empirically defined and how far it is to be equated with or distinguished from a class. If the approach to elite studies favoured by Scott has a long but largely sterile past, that favoured by Savage would scarcely seem, on the evidence so far available, to have a fruitful future.

\footnotetext{
${ }^{15}$ K. Hecht, D. McArthur, M. Savage and S. Friedman, Elites in the UK: Pulling Away? London: Sutton Trust., 2020.

${ }^{16}$ It is also relevant to note that Piketty's claim of a return to the belle epoque relates specifically to the fact that again today, in contrast with the situation in the first half of the twentieth century, those in the top percentile of the French income distribution derive their income about as much from inherited wealth as from their own labour. He is little concerned with questions of sociocultural attributes.
} 


\section{A NEW APPROACH}

Although the ways in which Scott and Savage would see elite studies as being best revived are quite divergent, there is one feature they have in common: both appear unduly restrictive. It is not apparent why it should be so exclusively important to treat as elites only those groups that can be directly associated with the exercise of power or to consider elites only within the context of class analysis.

We would suggest that elite studies might be better pursued if the full diversity of elites were to be recognised and, in turn, a much wider range of issues taken up than those on which Scott and Savage would wish to concentrate - but at the same time with a clearer specification of the kinds of research that would be necessary if progress is to be made.

We would wish to work with a broad understanding of elites - of the kind that Scott deplores - as being leading groups, in any area of social life, whose pre-eminence is in some way recognised and is associated with high rewards of a material and/or symbolic kind. Insofar as what we would propose has precursors, we would refer back to the study of French elites, remarkable for its time, directed by Alain Girard. In this work, the focus was on 'success' - on who succeeds in gaining access to elite positions in different areas of social life, through what processes of social selection, with what degree of variation in these processes from elite to elite, and with what societal consequences. ${ }^{17}$

We realise that in making our - or indeed any other - conceptualisation of elites operational for research purposes, difficulties are always likely to arise as to where boundaries should be

\footnotetext{
${ }^{17}$ A. Girard ed., La réussite sociale, Paris, Presses Universitaires de France, 1961.
} 
drawn between elite and non-elite. However, we believe that such difficulties can be significantly mitigated in two ways.

First, it would seem important that some sense of relevant orders of magnitude is preserved. Elites we would regard as numbering in tens, hundreds or, at very most, the low thousands in contrast, say, to social classes that can number in hundreds of thousands or millions. Such a numerical limitation of elites would seem in line with more general understandings of elites. For example, the thirty or more elites considered by the SMC range in size from 23 , Cabinet Ministers, to 650, Members of Parliament, but with most falling in the range of 100-350.

Second, in order to avoid more or less arbitrary decisions by the analyst, or others, we would see advantage in defining elites, so far as is possible, by some kind of institutional or associational reference. That is, according to their members holding designated high-level positions, as, say, within the political, governmental, judicial, corporate or cultural worlds; or as being members of specifically selected collectivities, such as political assemblies, scientific or cultural academies, or national sports teams. Where this is not possible, an elite might be defined in terms of those at the peaks of certain rankings, such as, say, rich lists, sports rankings or 'hit' charts, at least where these rankings would appear to be based on appropriate coverage and criteria. Only as a very last resort would we wish to follow what has become known as the 'reputational' method, where elites are determined by the judgements of supposed 'experts' or 'insiders'.

One direct consequence of our understanding of elites as 'small- $\mathrm{N}$ ' entities is that it becomes both practicable and desirable for them to be studied in toto: i.e. without sampling. What should be involved is an exercise in prosopography, a method of creating 'collective 
biographies' for long pursued by historians. ${ }^{18}$ Ideally, a complete list is to be compiled of all the members of an elite at a certain time or over a certain period and, for every individual included, biographical information collected of a range relevant to the research questions to be addressed.

What, then, are these questions central to the problematic of elites that we envisage? We would identify four of a closely interrelated kind.

First, the question of elite members' social characteristics, and in particular as relating to their social origins, must remain of importance. As will be seen, this question - of where from within society at large elite members are recruited - is basic to the others we consider. We would, however, observe that in past research its treatment has often been surprisingly deficient. Elite members' social origins, as indicated by attributes of their parents, have not in fact been established, or at best only very crudely. The focus has rather been on elite members' education - and chiefly, it would seem, because information on this tends to be fairly readily available from works of reference, such as Who's Who? and various directories. ${ }^{19}$ Such information may of course be of interest in itself, insofar, say, as it can throw light on uniformities in beliefs, values and sociopolitical orientations prevailing within particular elites - although family influences, we would suspect, are of generally more importance in this regard. But what can be dangerously misleading, as demonstrated some time ago by

\footnotetext{
18 See e.g. L. Stone, 'Prosopography', Daedalus, vol.100, 1971, pp.46-79; K. S. B. Keats-Rohan ed., Prosopography Approaches and Applications: A Handbook, Oxford: Oxford Unit for Prosopographical Research, 2007.

19 In the British case, see, for example, D.H.J. Morgan, 'The Social and Educational Background of Anglican Bishops - Continuities and Changes', British Journal of Sociology, vol. 20, 1969,pp. 295-310; W.L. Guttsman, 'The British Political Elite and the Class Structure' in Stanworth and Giddens eds., Elites and Power in British Society; P. Barberis, The Elite of the Elite: Permanent Secretaries in the British Higher Civil Service, Brookfield, Dartmouth Publishing, 1996; and more generally, D. Boyd, Elites and their Education, Slough, NFER, 1973.
} 
Rubinstein, is for elite members' education to be taken, implicitly if not explicitly, to stand as a proxy for their social origins. ${ }^{20}$

Thus, in the most recent SMC report on elites, that of senior judges is taken as the most exclusive in that it has the highest proportion of members who had attended private schools $65 \% .{ }^{21}$ But the question is not raised of how far the remaining $35 \%$, who went to state schools, differed in their social origins from their privately educated counterparts. Was there any larger proportion coming, say, from working-class families? It could be doubted. And, similarly, it is uncertain whether the conclusion reached by Reeves et al. in their study of entrants to Who's Who, that the ability of Clarendon and HMC schools 'to deliver elite destinations' has significantly declined can be taken to imply a corresponding decline in the ability to do so of more socially advantaged parents. ${ }^{22}$ The authors in question do acknowledge the problems that arise but the limitations of their data source mean that they can do little about them.

In future studies of elites we would therefore see it as essential to go beyond readily available, though often inadequate, 'big data' and to obtain good quality information on elite members' social origins in terms of some measure of parental socioeconomic position. While documentary and web searches can be of value in this regard, it is likely that in most cases survey research will also be necessary. The difficulties that may arise with such research tend to be exaggerated. For example, the SMC has argued - though on what grounds is unclear that many elite members 'are understandably unwilling to share detailed information on their

\footnotetext{
${ }^{20}$ W. D. Rubinstein, 'Education and the Social Origins of British Elites, 1880-1990', Past and Present, vol. 112, 1986, pp.163-207.

${ }^{21}$ Elitist Britain 2019.

${ }^{22}$ A. Reeves, S. Friedman, C. Rahal and M. Flemmen, 'The Decline and Persistence of the Old Boy: Private Schools and Elite Recruitment 1897-2016', American Sociological Review, vol. 82, 2017, pp. 1139-1166.
} 
circumstances while growing up', and that focusing on their education is therefore justified as 'looking at a characteristic which could be collected in a practical, consistent and unintrusive way'. ${ }^{23}$ Our own experience would suggest that if elite surveys are appropriately prepared and conducted, elite members can in fact show a readiness to participate and that response rates need not be unduly low. ${ }^{24}$

The second research question that we would identify concerns what might be called the formal processes through which elites are constituted. If one takes the wide-ranging view of elites that we propose, what is evident is the degree of variation that exists in such processes. One issue that arises from this variation is then the extent to which access to elites could be regarded as 'meritocratic', in the sense of being determined by individuals' own demonstrable achievements, rather than resulting from some form of choice by others in which merit, however understood, may or may not be a primary consideration.

An example at one extreme would be that of elites in individual sports, such as tennis or golf. These elites could be regarded as essentially meritocratic in that they derive from rankings that follow automatically from players' performance against their rivals: no choice by others is involved. Business, or at least entrepreneurial, elites might also be regarded as being to some significant extent self-selected. At the other extreme, an example would be British Cabinet or government ministers in general - a political elite chosen simply at will by the Prime Minister of the day from among members of the Houses of Parliament. In-between, one has elites where access is determined by choice in the form of selection by designated bodies, such as

\footnotetext{
${ }^{23}$ Elitist Britain 2019.

${ }^{24}$ In connection with a study of the formation of the British scientific elite from the start of the twentieth century, we have carried out an online survey of present Fellows of the Royal Society and obtained a response rate of close to $70 \%$. Other elites may of course prove less co-operative but this remains to be seen.
} 
appointment or promotion boards, or in the form of election, whether by existing members of the elite or some wider constituency. And combinations of selection and election are often in operation.

It would therefore be of sociological interest to see how far any relationship exists between the different processes through which elites are constituted and their members' social backgrounds and other characteristics. Is it the case that those elites that are in some way selfselected through performance tend to show the greatest social diversity - or again that there is less social skew in elite recruitment where processes of election predominate over those of selection? In elite studies hitherto such issues would appear to have attracted little attention, though no serious problems would appear to stand in the way of their investigation.

The third research question that would be central to our approach to elite studies follows on directly, and relates to what we would call the 'pools' from which elite members are drawn and to their social composition. The key issue to be addressed is that of how far social skewness in elite membership, in regard to social background - or, say, to ethnicity or gender - derives from what we have referred to as the processes through which elites are constituted, and how far from a similar skewness in the pools in relation to which these processes operate.

For example, while the immediate access to tennis or golf elites is based essentially on competitive performance, entry into the pools within which the competition occurs would appear to be strongly conditioned: that is, on account of the costs involved - for example, in regard to equipment, coaching, travel to tournaments and so on - as well as through sociocultural barriers. ${ }^{25}$ In contrast, it may be that with some elites the pools from which they

${ }^{25}$ On tennis, see D. Berry, A People's History of Tennis, London, Pluto Press, 2020. 
are drawn are less socially restricted than is the elite itself. That is to say, the social skewness of the elite is significantly intensified by the processes through which it is formed from within the pool. Suggestions have been made that, as a result of - perhaps unwittingly - biased promotion procedures, a situation of this kind has emerged in Britain in the case of the civil service, the military and the church, although we are not aware of any conclusive research. ${ }^{26}$ In investigating the relationship between elite and pool, an obvious issue is that of how pools are to be defined. This would seem fairly straightforward insofar as an elite stands at the peak of an established hierarchical structure of positions or where an elite body exists in a specific relation to a more or less well-defined collectivity - as, for example, with prestigious academies in relation to those engaging in scientific or scholarly research. But in other cases establishing the pool will clearly be more difficult, and in some instances it may be necessary to resort to the analysis of the career paths followed by existing elite members, with due regard for possible distortions that may in this way result.

Once pools have been defined, comparisons can then be made, in relevant respects, between the social composition of an elite and of its pool rather than simply between the composition of an elite and that of the population at large, which has been the more usual practice. Information on the social composition of pools is again likely to be dependent on survey-based research; but in many, if not most, cases such information should be available for sufficient

\footnotetext{
${ }^{26}$ In S. Friedman, Navigating the Labyrinth: Socio-economic Background and Career Progression within the Civil Service, London, Social Mobility Commission, 2021, it is suggested that while initial recruitment is based on fair and open competition, 'getting on' as opposed to 'getting in' is conditioned by a series of 'rules of progression' that favour those from more advantaged socioeconomic backgrounds and disfavour others. However, relevant evidence comes only in the form of the author's impressions from interviews with a small and not obviously representative sample of civil servants.
} 
numbers of individuals within the datasets of large-scale national surveys that are in the public domain.

Assuming, then, that the extent of social skewness among elite members can be more reliably established than before, and likewise the ways in which such skewness is created, the fourth and final question in the research programme that we would suggest concerns the wider issues for which its findings would carry implications. Two such issues seem of main importance.

First, insofar as the social origins of elite members are skewed, normative issues arise over inequality of opportunity. As the SMC has it, elite positions are those with 'the highest prestige and wealth' and 'among the most coveted in society', and therefore making such positions 'accessible to those from all backgrounds is an essential component of a society which cares about fairness and equity. ${ }^{27}$ In regard to any policy aimed at reducing inequalities in the chances of success in achieving elite positions, a better knowledge of the sources of these inequalities - of how far they result from the processes through which elites are constituted and how far through the composition of the pools within which these processes operate would be of obvious relevance.

Second, the foregoing issue can be also be expressed in terms of the wastage of talent - of the range and diversity of human resources - that is likely to follow from unwarranted disparities in the chances of elite access, and with then potentially adverse consequences for the quality of elites and for their effectiveness in performing whatever roles, and meeting whatever responsibilities, fall to them. Research on elites involved in the exercise of power has typically focused on the extent to which these elites, to use Scott's word, 'dominate'. That is, use their power in ways that are, implicitly if not explicitly, taken to be often illegitimate, in order to

\footnotetext{
${ }^{27}$ Elitist Britain, 2019, p. 13.
} 
maintain their positions and to further their own interests or those of the social groups or strata from which they are primarily recruited. Far less attention has been given to the degree of success of elites in pursuing those objectives that could be regarded as their legitimate concern. Some illuminating examples for future research do, however, exist.

Thus, historians have debated how far in the later nineteenth century the preoccupation of at least second generation British business leaders with securing social, rather than continuing entrepreneurial, success - perhaps as a result of their 'public school' education - was a source of national economic decline. ${ }^{28}$ And King and Crewe have analysed the 'blunders of governments' resulting from 'group think' among elites of similar social background and from the 'cultural disconnect' consequently existing between them and large sections of the population at large. ${ }^{29}$

The question of the quality and effectiveness of elites, considered in relation to social skewness in their recruitment, would in fact seem destined to become one of increasing public concern. There has already been much discussion of how far the quality of various sporting or cultural elites in Britain is impaired by social factors limiting entry into the pools from which they are drawn or biasing the chances of success within these pools. And the quality of other elites political, governmental and scientific - can only be expected to become an issue of rising importance in the context of the challenges now being raised by actual or potential economic, environmental and public health crises.

\footnotetext{
${ }^{28}$ M. J. Wiener, English Culture and the Decline of the Industrial Spirit: Britain 1780-1980, Cambridge, Cambridge University Press, 1981/2004; W. D. Rubinstein, Capitalism, Culture and Decline in Britain 1750-1990, London, Routledge, 1993; F. M. L. Thompson, Gentrification and the Enterprise Culture: Britain 1780-1980, Oxford: Oxford University Press, 2001.

${ }^{29}$ A. King and I. Crewe, The Blunders of our Governments, London, Oneworld Publications, 2013.
} 
In this regard, the most promising way of working would be to begin with a series of specific cases, and then to go on to consider how far the performance of elites in these cases can be associated with their recruitment and social composition. An example of obvious present-day interest, on which a rapidly growing amount of research is now in fact being undertaken, is that of the degree of effectiveness of different national elites in responding to the covid pandemic. A scathing analysis of the British performance at the start of the pandemic is provided by Horton, in which 'group think' is again suggested as a damaging factor. ${ }^{30}$ But what might also emerge as a longer-term problem are differences in the social origins, education and associated values and commitments among the several elites involved, so that, as a result of diverging priorities, cohesion in policy and action is undermined.

\section{CONCLUSIONS}

After a period in which interest in elites among social scientists went into decline, it is now reviving. But, if new research is to be productive, it is important to understand why the previous decline occurred. We have critically examined the largely contradictory explanations put forward by Scott and Savage. We would agree with Scott, as against Savage, that it is an internalist rather than an externalist account that is required - and also on the need for elites and social classes to be clearly differentiated. However, we would see the study of elites as having stalled primarily as a result of the very focus on the relation between elites and power, in the sense of domination, to which Scott urges a return. Where in this connection analyses have been made - and are now again being made - of the recruitment, social connections and

\footnotetext{
${ }^{30}$ R. Horton, The COVID-19 Catastrophe, London, Polity, 2020.
} 
cohesiveness of elites, the difficulty persists of showing what then distinctively follows for the ways in which, and ends towards which, elites actually use their power. Savage sees the decline of elite studies as resulting from their marginalisation within social stratification research and calls for their reintegration into class analysis. But the research programme he has initiated is marked by considerable confusion as a result of no clear position being taken on how, if at all, elites and classes are to be conceptually and empirically distinguished.

A further objection that we have raised to Scott's and Savage's proposals alike is that they imply a narrow limitation of elite studies for which no clear rationale is provided. In contrast, our proposals for the renewal of the field are based on an understanding of elites which covers leading groups in all areas of social life but which at the same time entails recognising elites as small-N entities that have as far as possible to be provided with some degree of institutional or associational definition. This in turn allows for a prosopographical treatment of elites as the starting point of research and, following from this, we propose a series of research questions that, in combination, form a new problematic for elite studies.

The question of the social origins of elite members remains of importance but we emphasise the need to treat this question more seriously than has often been the practice in the past. That is, through seeking information that allows the socioeconomic position of their families of origin to be directly and comprehensively established and removes any need for the use of education as a proxy. In this way, the degree of social exclusiveness of elites, and the extent of differences among elites in this regard, will be more reliably determined.

Questions of the ways in which elites are formed then naturally arise. As regards skewness in the social backgrounds of their members, attention should centre, on the one hand, on the processes through which elites are actually constituted, which can be shown to vary 
considerably, and, on the other hand, on the pools from which elites, however constituted, are drawn. Research in which both these questions have been addressed has so far been surprisingly limited. But, apart from its academic interest, such research would be of obvious importance in informing attempts at widening elite recruitment, whether made through public policy or by elites themselves.

Finally, insofar as social skewness is apparent in the composition of elites, concerns follow with questions both of equality of opportunity and of potential wastage of talent, and in turn with the implications for the quality and effectiveness of elites. With our wide-ranging view of elites, critical attention is drawn not only to the uses, or abuses, of power by elites but also to the question of the level of performance that elites attain in whatever field it is in which they hold positions of pre-eminence.

In short, a programme can be set out for the future of elite studies which would significantly extend their range, for which appropriate methods of data collection and analysis are available, and through which actual progress might be achieved to a greater extent than has previously been the case. 
